\title{
Proactive adaptation
}

\section{Scientists' coping strategies in an evolving research system: the case of life scientists in the UK}

\author{
Norma Morris and Arie Rip
}

Scientists in academia have struggled to adjust to a policy climate of uncertain funding and loss of freedom from direction and control. How UK life scientists have negotiated this challenge, and with what consequences for their research and the research system, is the empirical entrance point of this paper. We find that policy impacts can be modulated and buffered by strategies and compromises devised and deployed at research performer level. This shifts conceptualisation from terms of responses to one of more or less proactive strategies of scientists and science organisations which add up, intentionally or unintentionally, to shifts in the overall system.

Norma Morris is in the Department of Science and Technology Studies, University College London, Gower Street, London WC1E 6BT, UK; Tel: +44 207679 3703; Email: norma.morris@ucl.ac.uk. Professor Arie Rip is in the School of Business, Public Administration and Technology, University of Twente, PO Box 217, 7500 AE Enschede, The Netherlands; Tel: +31534893345; Email: a.rip@utwente.nl.

The empirical work was funded by the UK Economic and Social Research Council (grant no. R000222175). We are grateful to the case study departments and to others who agreed to be interviewed for the study for their cooperation and support.
N CIENTISTS IN ACADEMIA - faced with governments' requirement for relevance (Rip, 1997), a new insistence on accountability and management (Braun and Merrien, 1999), and retrenchment in public funding - had to adjust to the loss of what many had come to regard as a right: the 'right' to grant funding and the 'right' to be free of direction and control (Rip, 1994). How life scientists in the UK have negotiated and survived these challenges, and with what consequences for their research and the research system, is the empirical entrance point of this paper. We find that policy impacts can be modulated and buffered in a variety of ways, not least by strategies, both collective and individual, and strategic compromises devised and deployed at the research performer level. This might lead to the cynical conclusion that the most striking effect of policies on research is the development of a series of elaborate countermeasures. But these measures are not merely neutralising. They are rather the scaffolding supporting researchers' adaptation to new circumstances, providing a platform for 'give and take' behind which the system and its institutions continue to evolve.

This is the topic we address in this paper. It can be marked as a shift from a conceptualisation in terms of responses, to one of more or less proactive strategies of scientists and science organisations which add up, intentionally or unintentionally, to shifts in the overall system.

The empirical work on which this study is based took place primarily in the biological sciences departments of four English universities in the years 
Norma Morris has been a research fellow at University College London since 1996, having previously spent some years as a senior manager and policy-maker at the UK Medical Research Council. Her research interests are in science policy and research governance, impacts of new technology on regulatory research, and the role of volunteer research subjects in biomedical research.

Arie Rip is professor in Philosophy of Science and Technology at the University of Twente, the Netherlands. His research interests are science dynamics, sociology of technology and (constructive) technology assessments.

1997 to 1999 . The methodology has already been described in previously published articles (e.g. Morris, 2002a). In brief, departments were selected on criteria including research commitment, postgraduate training programme and representation of the main types of UK university. In each department, a cross-section of members was interviewed; interviews were also held with administrators and managers at departmental and university levels. Their responses were compared with what funding bodies said about their policies in corporate plans, strategy documents and official notices. These data were supplemented by interviews with representatives of major stakeholders and by studies of grant conditions. Documentary sources included both published and confidential papers and reports. In total, 56 interviews were conducted, involving 74 people.

Although there have been modifications to policy since the main fieldwork was done, the data remain valid for our analysis of strategic repertoires and multi-level interactions which operate over extended time-scales. The most significant change in the last five years has been the rise of some $£ 1.5 \mathrm{bn}$ in government investment in science. But the funding is predicated on a sustained belief in the key role of science for the UK's future prosperity and is coupled with policies designed to steer science to faster achievement of those economic goals (see for example DTI 2005). While the basis of government funding for science remains wealth creation and proactive policies to this end, requirements for accountability and working with users (especially industry), and mechanisms to steer research agendas will remain firmly in place. Despite the overall increase in funding, competition for grants remains stiff, and the main planks of government science policy differ little from those of the early 1990s (OST, 1993) in terms of the potential threat to scientists' independence and livelihood and the strategies they evoke.

We have chosen the biosciences as the site of investigation since their comparatively recent rise to national importance, continuing economic potential and still evolving organisational structure both give them topical interest and make them a good site for studying change and adaptation. Perhaps as a result of their rapid development, life sciences have lagged behind physics, chemistry and engineering in developing a formalised collective identity (forming the umbrella organisation Biosciences Federation only in December 2002). This may underlie the bias we have observed among life scientists towards strategies that operate either over science as a whole or at the individual or group level, with rather slower development of proactive responses at the intermediate level of department, school or centre. Overall, it seems likely that the marked growth and rapid development of biosciences will encourage organisational flexibility and transdisciplinarity (viz. the emergence of biophysics; Chadarevian, 2002) while their tradition of engaging with medical and environmental users may make for open-mindedness towards some of government's policy goals. Thus biosciences may be expected to be a fertile ground for the development of constructive strategies for 'answering back' to top-down policies.

\section{General perspective}

In what sense might scientists' strategic responses to policy be said to contribute to a scaffolding for adaptation? We have to locate such responses in an evolving multi-level system. The building blocks for such a perspective are available. In this section we sketch the overall picture. In the next section, we focus on the clusters of interacting strategies that we encountered in our empirical study.

\section{Multi-level systems analysis}

Scientists' responses have to be viewed in the context of the wider research system in which they operate. We conceptualise a research system as a multi-level social system held together by mutual interdependencies (Rip and Van der Meulen, 1996). The system comprises a macro level of government, a meso level of institutions (such as research councils, funding councils and coordinating bodies) having the task of refining policies and designing and resourcing programmes for implementation, and the micro level where programmes and policies translate into action by research performers (Braun, 1993; Van der Meulen and Rip, 1998). Each level has its own attributes and to a large extent its own dynamic, but its development is influenced by and influences the development of the others.

\section{In times of change boundaries change, roles evolve, new institutions may be created and new actors may enter the field: so that the nature of the interdependencies changes}


However, in times of change boundaries change, roles evolve, new institutions may be created and new actors may enter the field: so that the nature of the interdependencies changes (Rip and Van der Meulen, 1996). Positioning an analysis of the effects of science policy within this multi-level, multi-actor framework enables us to indicate how some of the strategies developed by research performers in the face of policy requirements may reshape or reinforce interdependencies across the levels of the system and thus contribute to its evolution. It also directs attention to structural features of the system, such as the significant presence in the UK of meso-level mediating institutions heavily populated by scientists and ex-scientists, which can be exploited by research performers to their own advantage.

\section{Principal-agent theory}

Within this multi-level framework, we use principalagent theory to help to understand how scientists' strategies may nuance the working relationships across levels. Principal-agent theory originated in contract theory economics, as a means of understanding and managing the relationship between the principal and his contracting agent, and the costs that this entails. The theory has required much adaptation and development for use in wider contexts (Moe, 1984; Coleman, 1990) and specifically for application to research systems (for a succinct overview see Braun and Guston, 2003). But the central concept of the principal (who has the resources) needing to delegate to an agent (who has the skills) to achieve his or her goals, and the generic problems and strategies that managing this relationship entails, has proved useful in illuminating some aspects of patterns and tensions occurring in research systems (Braun, 1993; Guston, 1996; Caswill, 1998; Van der Meulen, 1998).

One added complexity in a layered research system is ambiguity over who is principal and who is agent. Government is the ultimate principal, but rarely delegates directly to the research-performer (micro) level. Most research systems have an intermediary level of research council, to whom government delegates responsibility for deployment of research funds. Research councils are thus agents of government but must then themselves delegate to the scientific community for performance of the actual research tasks. Scientists as agents thus usually relate to a research council (or other intermediary body) as their principal. The strategies we have observed scientists using therefore tend to be directed at relationships with their immediate principal - the intermediary bodies rather than government itself.

\section{Micro-level dynamics}

Third, we consider researchers' responses to policy from the point of view of how they contribute to or tend to modify the dynamics at the micro level, drawing on the ethnographic investigations of 'the real-time processes' of scientific knowledge production undertaken from the late 1970s (see for example Knorr-Cetina, 1994). Dealing with the demands of science policy requires the enlargement of 'political' activity and processes of articulation (Fujimura, 1987) that have to be conducted across levels of the system to accommodate the interests of policy makers, sponsors and users as well as of researchers' own institutions and peer networks. This may lead to a de facto redefinition of what it means to do research.

There are questions too about how researchers deal with the pressures to shift research direction generated by policies for steering the research agenda. The culture (and career structure) of scientific research in universities requires each researcher to aspire to running his or her independent research programme. To this end young researchers need, as soon as local custom allows, to demonstrate their capacity for original and independent work that will buy reputation and recognition by peers. A policy that constrains choice of research topic is both a practical threat to this progression (by reducing eligibility for funding) and a challenge to the notion that 'independence' normally includes control of the scientific agenda (Morris, 2002b). Such a policy is equally a threat to more established scientists who risk loss of their cultural capital (built up over many iterations of the 'credibility cycle'; Latour and Woolgar, 1979) if they change their research field (Ziman, 1987; see also Mulkay, 1972) under financial pressure.

Following from this we conclude that the internal dynamics of the micro level as they relate specifically to policy requirements will drive researchers, encircled with a multiplicity of pressures in their daily lives, to be selective in their attention to policies, and to aim to manage them in the context of other competing demands.

\section{Managing complexity}

Figure 1 attempts to capture how, from the research performer's viewpoint, external policies must compete for attention with other equally pressing issues

The kind of considerations researchers must deal with can be fleshed out from the empirical studies as follows:

- Whether they are keeping up with the science, their competitors, the latest techniques, and the end of the era of the 'man and dog' team in biological sciences.

- Legitimate ways of managing the increased pressures of global competition: should they share information less readily? Can they negotiate with competitors to divide up the patch, or defuse head-to-head competition by agreeing on simultaneous publication?

- The stage of an individual's career: does the researcher need quick results to bolster his or her 


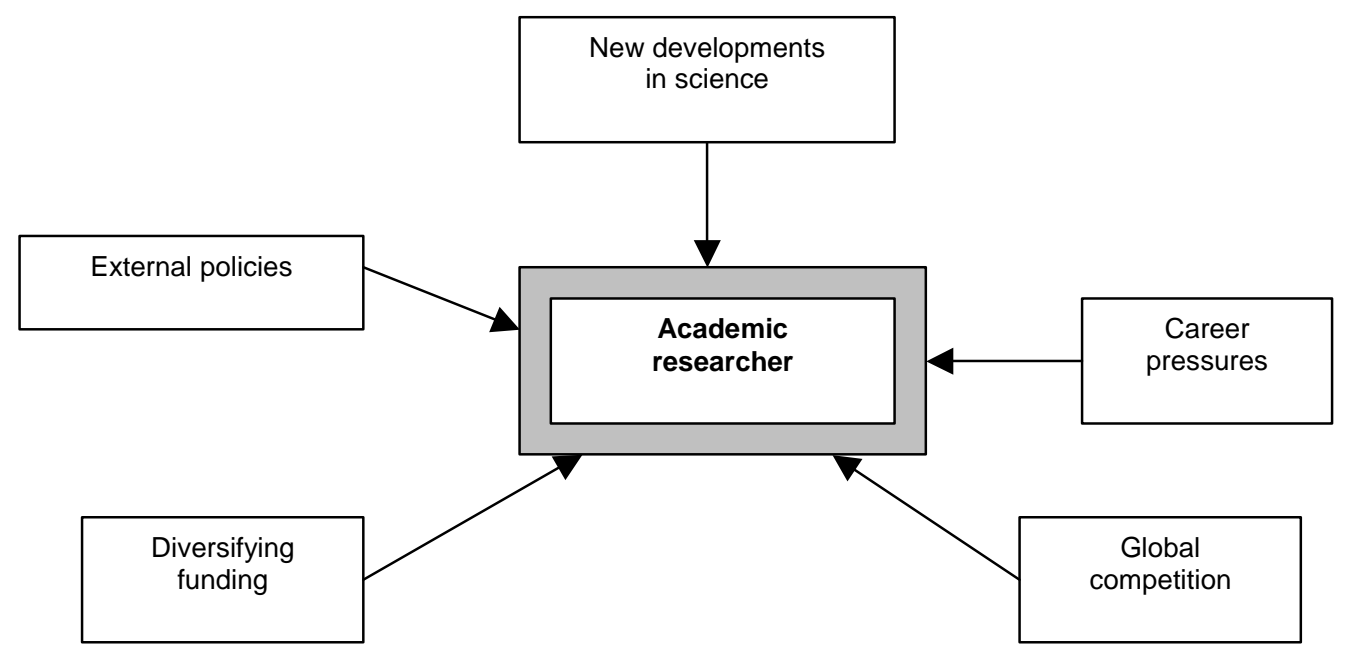

Figure 1. Heterogeneous preoccupations of academic scientists

next job application? Is he or she senior enough to get a five-year rather than a three-year grant? Will working on an industry-funded project adversely affect promotion prospects?

- How vulnerable is the group's funding - how might they hedge the risk? One way is to do work for industry or other users (e.g. government departments) to gain access to new money or provide a small pot of funds from contract work useful for 'tiding over' or getting new work started. Another is to spread one's favours (i.e. grant applications) to avoid being dependent on one particular sponsor.

These researcher preoccupations are likely to affect the degree to which researchers will be aware of or take issue with external policy requirements or initiatives. Reactions to policy will be geared to how far they are judged likely to affect funding or career prospects, or the ability to complete work satisfactorily (e.g. the time-consuming aspects of increased accountability). Thus responses will range from overt stratagems to counter perceived disruptive effects through more covert reinterpretation and appropriation of selected elements in the service of other aims, to indifference where non-compliance is seen as posing little risk (e.g. engaging with the public; Morris, 2000).

\section{Coping and countervailing strategies}

Policies are designed and formulated primarily at the macro and meso levels for implementation by research performers at the micro level. These policies may often have as their aim changing the existing practices and culture of the micro level. We interpret the countervailing strategies that scientists develop not as mere blocking tactics, but rather as an attempt to manage the pace of change, to re-assert or represent their own core values, and to improve the security of their funding. The strategies are a way of 'buying time' for both themselves and the policymakers to evolve towards some more stable form of modus vivendi. The strategies can accommodate gradual shifts in scientists' own positions as well as influencing policies and policy-makers.

The two main destabilising features of government policies of the 1980s and 1990s may be crudely summarised as the threat to scientific independence and the threat to continuity of funding. The two are of course interrelated since getting funding may now often require some compromise on topic of research and acceptance of more stringent conditions of accountability. At the same time, the culture of individualism and scientific autonomy is still part of the self-image of university scientists, nearly half a century after the publication of The Republic of Science (Polanyi, 1962; Rip, 1994; Henkel, 2000a). When stating their personal priorities and criteria for success - in what appears to be a defensive stance - researchers put particular emphasis on freedom to follow their own ideas (Henkel, 2000a: 200; Morris, 2002b). This reflects the residues of an idealised view of freedom of inquiry, the normal requirements of building a reputation, and a lifestyle choice in favour of the academic life, for all its insecurity and low pay, because "I want to do what interests me".

Published studies of scientists' response to policies spanning the period from the 1980s onwards make reference to the strategies that scientists employ, but vary in their assessment of the importance and pervasiveness of these strategies. These variations may reflect differences in the time and place of the studies. Hackett (1987) for example finds US neuroscientists only just coming to terms with the absence of discretionary funding, tougher assessment standards and closer accountability for grants. $\mathrm{He}$ finds some scientists engaging in strategic compromises, but notes other more negative reactions (such as opting for 'safe' projects and exploiting assistant staff) that could be damaging in the long 
term. Ziman (1987) is basically sanguine about scientists' ability to adapt positively, and argues that the problem in the early 1980s in the UK was the "abrupt, involuntary changes" forced on them by science policy, with insufficent time to smooth and legitimise their transitions.

Schimank and Stucke (1994), writing from a European perspective, sound a gloomy note in their title of Coping with Trouble, and provide a classification of "coping" which includes a category of "suffering" and one of "defensive coping" (i.e. downsizing). Though all their categories can still be recognised today, in the UK at least the effects of early retirements, along with redeployment of staff into teaching or administration, has left a research population selected for "active coping", and this affects the balance of active and passive approaches. Both Henkel (2000b) and Trowler (1998) (the latter in the context of higher education reform) characterise UK academics as highly proactive in their response to policies. As Henkel says, academics should not be understood as "passive recipients" of policy, but "as an active population ... able to draw on well institutionalised, as well as individual, strategies to obtain the means to obtain their ends" (Henkel, 2000a). Our data on UK life scientists supports a similar view.

\section{Four clusters of interacting strategies}

Under the post-World War 2 formula of Science: The Endless Frontier (Bush, 1945) the goals of scientific independence and of continuity of funding could be combined, but now trade-offs are necessary, or "managing the pace of change". This includes shifts of own goals (new practices) as well as attempts to shift others. We discuss below four clusters of strategies through which scientists aim to control the impact and influence the direction of policies.

\section{Scientists' strategic use of 'science'}

Scientists often refer to 'science' as the main influence and driver of their professional lives. By this they appear to mean the whole amalgam of past and

\section{By 'science', scientists often appear to mean the whole amalgam of past and new knowledge, new enabling technologies, methodological discipline, intellectual fashion, and the successes of competitors}

new knowledge, new enabling technologies, methodological discipline, intellectual fashion, and the successes of competitors. They tend to present it as a power separate from and independent of the institutions of state, of policy-making and of research. It is offered as having its own dynamic and its own rules (witness comments such as "We must go where the science leads"; "That's not how science works").

This use of science (which we emphasise hereafter by capitalising the term) effectively makes of Science an "abstract sponsor" of research (Rip, 1997). As such, it is a useful construct for negotiations between scientists and their actual sponsors. At the same time, it draws strength and plausibility from encapsulating the recognised internal dynamic of science as an institution, whereby the internally generated agenda that arises from scientific advances creates new scientific opportunities and needs. Scientists may use it to support their claims or proposals, or may find themselves stranded because Science has moved on.

Research councils, as well as research performers, acknowledge its influence and use it in support of their strategic priorities under the rubric of "realising research opportunities" (RCUK, 2003). The Medical Research Council (MRC) has traditionally boasted of being "science-led", or "mission-led", not "financeled" (MRC, 1986: 1, 1995: 6, 11). More subtly, it offers its own science-led definition of what constitutes 'value for money' (and who shall be the judge of it) by reference to "scientific value for money" (MRC, 2002; emphasis added). By invoking Science as its driving force and arbiter of its decisions, MRC reinforces the existence and power of this abstract sponsor and potential buffer against undue influence from MRC's actual sponsor, government.

In principal-agent terms, Science acts as one of the multiple principals that feature in many modern research systems. It offers not financial but symbolic resources; scientists engage with its agenda in the expectation of mutual benefit - successful and groundbreaking research that advances both science and their careers - and feel comfortable acting as the agent of Science. Following the dictates of Science, unlike following the dictates of government, is not perceived as a threat to 'scientific independence'.

Conventional principals, such as research councils, like to engage Science as a co-principal in their endeavours. Reference to Science creates a bond with the scientific community, and thus helps research councils strengthen their influence in the micro level of the research system without jeopardising their relationship with government. Research councils as institutions also value their independence and find, much like scientists, a more congenial rationalisation of their own position as agents by casting themselves as servants of Science rather than of political masters. This might be termed a strategy of 'reattribution' of policies in order to manage the threats they might otherwise pose. Additionally, in the same way as an alliance with industry and 
development of a common agenda with industry for example through foresight exercises - can positively shape the relationship of research councils with government, so may a lateral alliance with Science add to their authority with both government and the national community of scientists. 'Science' thus becomes an important strategic resource at both the micro and meso levels of the system, and by its potential to influence the balance of power between levels may contribute to the evolution of the system.

Co-existing with this use of Science, the "abstract sponsor", as a collective strategic resource, is a contingent use of Science to justify preferred ways of working, to blot out other pressures, or privilege decisions made by scientists. At interview, scientists cited the nature of science to claim immunity from certain kinds of accountability or direction; cited science rather than policy as the reason for their research choices; and were concerned, in the name of good science, about others than scientists taking decisions on science. Science used in this way is important both for the internal social organisation of the micro-world - reinforcing the institutions of self-governance such as peer review - and for negotiating boundaries and relationships across levels. It is a strategy that researchers deploy to help protect their personal and professional space.

The strategic use of Science is thus a strategy pursued at the collective level of the scientific community, including those cross-border members of the community who have chosen to inhabit the mesoworld of research councils or other science funding bodies. It is a potent device for reattributing actions (i.e. to scientific need rather than obedience to government) and thus maintaining scientists' self-image as independent academics.

The above strategies are premised on a distinction between the requirements of government policies and the interests of Science. It has been a common complaint of scientists since the 1980s that macro-level government policies for steering research fail sufficiently to recognise the authority of Science. The strong imprint of the work of 'purification' of science in the nineteenth and twentieth centuries and the Vannevar Bush doctrine of a free rein for science (Bush, 1945) has encouraged the assumption, not least among scientists, that strong government policies, especially those aiming at 'relevance', will severely constrain science and stultify future progress - despite ample evidence of both the historical and contemporary peaceful co-existence of relevant and basic research (Rip, 1997; Stokes, 1997). The continuing transformations that are taking place in the research process however (Nowotny et al, 2003) provide grounds to argue that scientists' position on this may be closer to government's than may at first appear.

Few in the academic community would choose to quarrel with the government view that the primary justification for public support for science is its potential usefulness to the nation. This was also the basis of Bush's case to the US Government back in
1945 (Bush, 1945). Though in the UK the explicit statement in the 1993 White Paper that the rationale for public support for science was "wealth creation" (OST, 1993) caused something of a frisson at the time (see for example Richmond, 1993; MRC, 2000), for the majority of scientists the concern was, and is, less about the principle and more about the degree to which the link between research and benefit might need to be direct and demonstrable. This was evident in the empirical data, both through direct statement and stories of unpredictable useful outcomes of research.

The UK Government, like many others, having built a significant part of its economic policy around science for many years, shares with the scientists a common vested interest in keeping alive faith in the benefits of science. Scientists may rationalise these benefits rather more expansively (including valuing research as "a cultural and intellectual pursuit"; RCUK, 2004) but in practice they and government work to a common cause of assuring that science can deliver. This helps create a climate for negotiation over science-specific policies and may encourage government to moderation over the imposition of ideology-driven policies (such as new managerialism) on science. Though seldom explicitly acknowledged, this is de facto a collective strategy for agents to agree common goals with the principal (an acknowledged way of reducing conflict in a principalagent relationship; Van der Meulen, 1998) and so contributes to maintaining a modified independence for scientists, as well as improving their funding prospects.

\section{Peer review and the research council world}

The instrumental use of Science is taken further in the way features of the internal social organisation of science have been crystallised out into the system of peer review for resource allocation and evaluation of results. This makes an interesting example of creative, and functional, infrastructure building. Science still carries some of the authority associated with the abstract sponsor, but it is operating under the control and serving the collective interests of its agents, the scientists.

The peer-review system serves to reinforce scientists' confidence in their collective independence and intellectual freedom, by bringing resource allocation under the umbrella of the wider academic peer review system, which "generates reputations and so helps to reinforce identities" (Henkel, 2000a). It bolsters scientists' assertion of their independence by providing some justification for their rhetorical claims (Mulkay, 1979; Gieryn, 1983) that they feel themselves primarily accountable to their peers. Peer judgements will also reflect shared views in the scientific community on topics and approaches that are most timely and promising so that the implementation of policy may subtly modulate it towards common goals. 
Peer review may also influence policy by providing a means by which the 'lower' levels of a multilevel system (here the research councils and the scientific research community) may constrain the decision space of the macro level, by requiring the legitimation by peer review of even the most strongly government-backed initiatives. They may set boundaries to how specific a top-down initiative may be, by retaining the ultimate say on whether the necessary scientific competence exists to enable a programme to go ahead; they may hold up or rechannel agreed programmes if there are concerns about scientific quality (the early days of the UK Government LINK programme for university/ industry collaboration were a case in point); and they constrain (to a point) the processes that the macro level can use for the allocation of resources without loss of legitimacy or prestige.

Peer review is a well-established (though not untouchable) part of the research system that scientists can use to modify the course of policies in their implementation and to act as an ally in their work of reinterpretation of policies.

While research councils and similar meso-level bodies have a particularly significant role as supporters of the peer-review system, they also have a well-recognised role as mediators of policy, and this enters into researchers' calculations. In the UK the meso level is dominated by research councils, whereas in other countries (e.g. the Netherlands, Sweden) there is often a more varied meso-level population. The hardening of the government attitude to science spending and public accountability of the later twentieth century caused a shift in the government-research councils' relationship to less trust, more monitoring and more planning. This cascaded down through the system, as research councils in turn applied these same accountability principles to the research performers, to shift research councils' relationships with scientists in similar directions. As intermediary bodies, the research councils have to grade these shifts finely. On the one hand they need to satisfy government of their commitment to government goals; on the other hand they need to maintain their closeness to the scientific community.

There is some evidence that, overall, UK life scientists make less use of this potential plasticity of the research councils than they might. At the level of the individual grant application, scientists make efforts to create productive relationships with the councils as funding bodies, and they rely on the councils (and their peer-review committees) to understand the problems of scientists and allow some latitude in their assessment of projects and their application of rules of accountability (Morris, 2003). But this is using the councils only to manage the pace of change, whereas they could do more. Councils, dependent as they are on the scientific community, are potentially a medium through which the community can introduce its own agenda into government policies. But this seems to work mainly through individual initiative of committee members and is rarely coordinated (except by the councils).

\section{Plurality of funding}

A further feature of the UK research system that provides strategic opportunities for research performers is the plurality of funding sources (multiple principals in principal-agent terms). Researchers have developed strategies for building good relations with many of these prospective sponsors, and for opportunistically migrating between them when a coincidence of research agendas occurs. Thus the presence of multiple principals in the science policy arena gives established agents the opportunity to seek a principal whose research goals are close to their own, or whose contractual terms and supervision practices are more congenial, and thus mitigate the sharp edges of the principal-agent relationship and its interference with their preferred research programme. For researchers embarking on their career the multiplicity of principals provides a choice of entry points. In this way, multiple funding sources offer opportunities for buffering the effects of more prescriptive policies and maintaining independence.

They also serve a significant function in adding to the security of research groups' funding. Group leaders commonly adopt the strategy of diversifying their sources of funding so as to hedge the risk of one sponsor pulling out abruptly. The risk of this is greater at times when sponsors have quite specific agendas and changing priorities. The added importance of diverse sources of funding to mitigate this insecurity has implications also for the growth of local institutional management. Part of scientists' strategic response to policies has been to develop departmental and central university management to provide new services such as dissemination of information about funding opportunities, public relations and strengthened administrative support. The departmental role is also extending into strategic scientific management, aligning the departments' development and recruiting plans with what are perceived to be the long-term funding opportunities. A further indication of how scientists' attitudes evolve in changing research environments is the general acceptance of the concept of there being a departmental programme and the degree of "direction" this implies (Morris, 2002a).

The presence of multiple funding sources, along with the need for security of funding, has also led to the development of an elaborate repertoire of strategies at individual and research group level to strengthen relations with sponsors, match agendas, or 'pick and mix' among schemes and funding sources. A detailed study of these group-level strategies, from a principal-agent perspective, is the subject of another paper, and we therefore do no more here than note their significance in enabling (and at times subverting) the implementation of policies and effecting a reconciliation (albeit often partial and 
temporary) between the sponsors' and the scientists' goals.

\section{The re-framing of working with industry}

In the hands of the academic research community, the policy requirement to "work with industry" seems to have been mutated, and in many cases attenuated, to fit better with researchers' personal predilections. UK Government policy statements stress the stimulus to the economy from innovation and exploitation and cite university spin-off companies and licensing agreements as measures of success (HEFCE, 2003; DTI, 2002). The emphasis is on entrepreneurship and industrially oriented innovation, and several special funding streams have been developed to aid these activities (DTI, 2002).

But although biotechnology, genetic manipulation and bioinformatics have brought the life sciences to the forefront of industrial interests, empirical studies suggest that academic entrepreneurship and technology transfer, though immensely grown in status and achievement, are still a passion of the few, albeit a prestigious and influential few. Much of the "working with industry" in university departments consists of routine contract work, consultancy, and some industry funding of postgraduate students. Academics can assimilate this into their normal way of life; their substantial funding and their mainstream research interests continue to be in the public sector (Morris, 2002b). There are examples from chemistry and engineering (Rip, 1997; Disco et al, 1992; Blumenthal et al, 1997) suggesting that biological scientists may not be typical in this respect. There is however also evidence of a choice of roles, with many preferring to remain academic, in outlook and in profession (Atkinson-Grosjean, 2005; Rosenberg and Nelson, 1994; Bird and Allen, 1989), and within life sciences indicative evidence of much pedestrian industryoriented research (Blumenthal et al, 1996, 1997; Howells et al, 1998; Cohen et al, 2001).

The UK Government has not seen fit to challenge this interpretation of its policy. It seems content to continue to allow academics this discretionary space, where they comfortably use industry as a form of income generation and still look for their intellectual stimulation and material reward to the academic world. While there are tensions implicit in this situation, there is some justification for life scientists' unspoken reinterpretation of the policy in the conclusions of analysts such as Senker et al (1998) who recommend that government should increase the number of communication channels rather than put the emphasis on large-scale formal collaborations. An optimistic view of the strategy of reinterpretation in this instance might be that it would buy time for a reconciliation of positions along these more inclusive lines.

Furthermore, non-entrepreneurial academics frequently choose to attribute their working with industry, not to the influence of government exhortations

\section{Non-entrepreneurial academics frequently choose to attribute their working with industry to their personal financial strategy for diversifying funding or creating a pot of contract income to use for their mainstream programme}

(however reinterpreted), but to their personal financial strategy for diversifying funding or creating a pot of contract income to use for their mainstream programme. The combination of the strategy of covert reinterpretation and the appropriation of selected elements in the service of other aims has an overall effect on the working of the micro level of the research system by reasserting and reinforcing the priority of local and professional concerns, and diminishing the visibility and influence of external policies.

\section{Conclusions}

A first general conclusion from this study of researchers in the life sciences is that these actors show adaptation, but not transformation. They have shifted their ideas and practices sufficiently to cooperate with a more intrusive policy regime, but without stepping out of their traditional academic framework and the matrix of concerns that shape an academic scientist's career. This has required some readjustment of their stereotypical self-image as scientists to give more prominence to resource mobilisation and management skills. The repertoire of strategies we have discussed forms an important tool for achieving this controlled adaptation and managing the continuing tension between freedom and control in their relationships with their sponsors and the threats to financial stability. Cumulatively the range of activities represents quite significant additions and extensions to the older, idealised concepts of what 'doing research' means, with activities outside the laboratory assuming increasing importance, and new skills needing to be developed for these tasks.

Of course, such political skills, though for a long time ignored, have always formed an essential part of a successful research career (Latour, 1987). But acknowledgement of their importance is becoming more general among practitioners. Although our empirical data was drawn only from biologi$\mathrm{cal} / \mathrm{biomedical}$ scientists, studies in the literature on other countries and other disciplines (AtkinsonGrosjean, 2005; Harman, 2005; Shove, 2000; Van 
der Meulen and Van der Most, 2002) suggest similar processes of adaptation and perseverance are taking place on a wider front.

Researchers' responses are of course embedded in a system. Historical and structural features of the system are important for the viability of researchers' strategies, and the synergies that may develop with other system levels (such as with the research councils over the use of Science as an abstract sponsor) reinforce the strategies' effectiveness and may influence how the system evolves. If one envisages government and the research performers as being at the two extremes of a linear scale, with research councils somewhere in the middle, then the councils can be thought of as moving nearer to the performers or nearer to government in accord with political or other pressures. Government initiatives in the UK in the 1980s and 1990s drew councils closer to government (e.g. through closer accountability and structural reforms announced in the 1993 White $\mathrm{Pa}$ per; OST, 1993). The shared strategy of referring to the authority of 'Science' tends to shift them back towards the scientific community.

A number of strategies on which researchers heavily rely, as they attempt to manage policies ranging from accountability to collaborating with users to steering of research, are tailored to exploit particular structural features of the system (like multiple funding sources) or operating practices (like peer review). For these strategies to remain viable such features need to persist. Plurality of funding and the shared faith in Science as an economic driver are deeply engrained in the UK system and they and researchers' strategies are likely to be mutually supportive. Thus researchers' strategies tend to strengthen and perpetuate these system features.

There may however be questions as to whether "peer review" as used in the policy field can endure in its present form in the light of pressures for "socially robust" knowledge (Nowotny, 2001; DoH, 2001; DTI, 2000), and whether researchers are strategically equipped to manage such a challenge. Modifications to date have not as yet undermined peer review's essential character as an aspect of scientific self-governance. The introduction of industry into formal decision-making was indeed one of the less disruptive parts of the science policy changes of the later twentieth century (since industry representatives often came from research divisions or shared a commitment to basic research; CBI, 1997; Senker et al, 1998); but it must be doubtful whether public participation could be assimilated so smoothly, since the public voice will be more heterogeneous and possibly more demanding. There could be effects on parts of the research system on which scientists now depend, such as the convergence of policy priorities with scientific trends.

Significant diminution of the voice of science in the peer-review process would require another significant adjustment for scientific researchers. 'The public' under such a regime would become another constituency for researchers to manage - and possibly to exploit. Industry can be useful to scientists (at both meso and micro levels) as a foil to government (see for example Van der Meulen, 2003) and an independent but non-disruptive voice in peer review. Strategies of reinterpretation, cultural harmonisation, and identification of specific projects of mutual interest might be developed to meet this further policy challenge.

Researchers' strategies are primarily designed to create a space for negotiation and manoeuvre. This allows them to sustain their work and possibly influence the evolution of the system. It is helpful that ambiguity and flexibility are pervasive within the UK research system. There are concordances and ambiguities at the heart of the system, which favour the construction of a fuzzy-edged scenario in which scientists can more easily combine (more or less satisfactorily) fulfilment of their scientific aspirations and compliance with a science-policy agenda.

Flexibility within the system derives from several interlocking strands: the shared commitment of government and scientists to the pursuit and furtherance of science; the ambiguity of government formulation of policies (being set out only in broad terms, with the details filled in by the science community); tacit understandings between grant recipients and research councils; and sponsors' condonement of including 'Science' as a kind of third party to sponsorship transactions with an assumed agenda of its own. This partly compensates for the relative paucity of consensus-building organisations in the meso-level of the UK system and creates space for scientists to accommodate their own agenda within programmes geared to the principal's objectives. While some specific flexibilities (like research councils' cavalier attitudes to some of their own accounting rules) may be ripe for tightening; others appear to be rooted in such fundamental propositions as the open-ended nature of scientific research or government's dependence on science-based economic growth, and would not be easily eradicable.

On balance, the findings from this study are positive regarding the resilience of research performers and the survival and growth of good and useful science through periods of adverse or disruptive change. Although a generation has passed since the main changes, the old issues are still debated, but the work of mobilising resources and gaining credit continues apace, with some readjustment of the balance of effort. Similar adjustments have been made in other countries (Braun and Merrien, 1999; Benner and Sandstrom, 2000; Atkinson-Grosjean, 2005; Behrens and Gray, 2001). Researchers' strategies of re-attribution, reinterpretation and exploiting system features allow continuance of aspects of the old ideology of science and its practice, and provide researchers with the room for manoeuvre they need, and a frame within which shifts can be made without seriously compromising an academic research agenda or their sense of intellectual integrity. 
We called researchers' strategies a scaffolding. Like scaffolding, they have rough edges, are functional rather than aesthetically pleasing, and though often staying in place a long time are ultimately impermanent. They are not solely a means of shoring up a crumbling edifice, but a platform behind which the work of repair, refurbishment and reconstruction of a battered system can go forward, while the business of academic research goes on.

\section{References}

Atkinson-Grosjean, Janet 2005. Public Science, Private Interests: Culture and Commerce in Canada's Networks of Centres of Excellence. University of Toronto Press, Toronto.

Behrens, Teresa and Denis Gray 2001. Unintended consequences of cooperative research: impact of industry sponsorship on climate for academic freedom and other graduate student outcome. Research Policy, 30(2), 179-199.

Benner, $M$ and $U$ Sandstrom 2000. Institutionalizing the triple helix: research funding and norms in the academic system. Research Policy, 29(2), 291-301.

Bird, Barbara and David Allen 1989. Faculty entrepreneurship in research university environments. Journal of Higher Education, 60(5), 583-596.

Blumenthal, D, E Campbell, M Anderson, N Causino and K S Louis, 1997. Withholding research results in academic life science: evidence from a national survey of faculty. Journal of the American Medical Association, 277, 1224-1228.

Blumenthal, D, N Causino, E Campbell and K S Louis 1996. Relationships between academic institutions and industry in the life sciences: an industry survey. New England Journal of Medicine, 334(6), 368-373.

Braun, Dietmar 1993. Who governs intermediary agencies? Principal-agent relations in research policy-making. Journal of Public Policy, 13(2), 135-162.

Braun, Dietmar and Francois-Xavier Merrien eds. 1999. Towards a New Model of Governance in Universities? A Comparative View. London: Jessica Kingsley.

Braun, Dietmar and David Guston, 2003. Principal-agent theory and research policy: an introduction. Science and Public Policy, 30(5), 302-308.

Bush, Vannevar 1945. Science: The Endless Frontier. Washington DC: United States Government Printing Office.

Caswill, Christopher 1998. Social science policy: challenges, interactions, principals and agents. Science and Public Policy, 25(5), 286-296

$\mathrm{CBI}$, Confederation of British Industry 1997. Investing in Research: Technology and Innovation Brief. London: $\mathrm{CBI}$.

Chadarevian, Soraya 2002. Designs for Life: Molecular Biology after World War II. Cambridge: Cambridge University Press.

Cohen, Laurie, John McAuley and Joanne Duberley 2001. Continuity in discontinuity: changing discourses of science in a market economy. Science, Technology and Human Values, 26(2), 145-155.

Coleman, James S 1990. Foundations of Social Theory. Cambridge, MA: Harvard University Press.

Disco, C, Arie Rip and Barend van der Meulen 1992. Technical innovation and the universities: divisions of labour in cosmopolitan technical regimes. Social Science Information, 31(3), 465-507.

DoH, Department of Health 2001. Research Governance Framework for Health and Social Care. London: DoH.

DTI, Department of Trade and Industry 2000. The Government Response to the House of Lords Select Committee on Science and Technology Third Report: Science and Society. London: DTI.

DTI, Department of Trade and Industry 2002. Investing in Innovation: A Strategy for Science, Engineering and Technology. London: DTI.

DTI, Department of Trade and Industry 2005. Science Budget Allocations: 2005-06 to 2007-08. London: DTI, May 2005. DTI/Pub 7841/1.5k/05/05/NP.

Fujimura, Joan 1987. Constructing "do-able" problems in cancer research: articulating alignment. Social Studies of Science, 17, 257-293.

Gieryn, Thomas F 1983. Boundary-work and the demarcation of science from non-science: strains and interests in professional ideologies of scientists. American Sociological Review, 48(6), 781-795.

Guston, David 1996. Principal-agent theory and the structure of science policy. Science and Public Policy, 23(4), 229-240.

Hackett, Edward J 1987. Funding and academic research in the life sciences: results of an exploratory study. Science and Technology Studies, 5(3/4), 134-147.

Harman, Grant 2005. Australian social scientists and transition to a more commercial university environment. Higher Education Research and Development, 24(1), 79-94.

HEFCE, Higher Education Funding Council for England 2003. Higher Education-Business Interaction Survey 2000-2001. Bristol: HEFCE. <http://www.hefce.ac.uk/pubs/hefce/2003/ 03 11.htm > last accessed 5 April 2006.

Henkel, Mary 2000a. Academic Identities and Policy Change in Higher Education. London: Jessica Kingsley.

Henkel, Mary 2000b. Academic responses to the UK Foresight Programme. Higher Education Management, 12(1), 67-84.

Howells, Jeremy, Maria Nedeva and Luke Georghiou 1998. Industry-Academic Links in the UK. Manchester: PREST.

Knorr-Cetina, Karen D 1994. Laboratory studies the cultural approach to the study of science. In Handbook of Science and Technology Studies, eds. S Jasanoff, G E Markle, J C Petersen and T Pinch. Thousand Oaks: Sage.

Latour, Bruno 1987. Science in Action: How to Follow Scientists and Engineers through Society. Cambridge, Mass.: Harvard University Press.

Latour, Bruno and Steve Woolgar 1979. Laboratory Life: The Social Construction of Scientific Facts. Beverly Hills: Sage.

Moe, T M 1984. The new economics of organization. American Journal of Political Science, 28(4), 739-777.

Morris, Norma 2000. Science policy in action: policy and the researcher. Minerva, 38, 425-451.

Morris, Norma 2002a. The developing role of departments. Research Policy, 31(5), 817-833.

Morris, Norma 2002b. Tower power: academics' commitment to the wealth creation mission. Industry and Higher Education, 16(6), 337-348.

Morris, Norma 2003. Academic researchers as "agents' of science policy. Science and Public Policy, 30(5), 359-370.

MRC, Medical Research Council 1986. Corporate Plan 1986. London: MRC.

MRC, Medical Research Council 1995. Corporate Plan 1995. London: MRC.

MRC, Medical Research Council 2000. Are We Realising Our Potential? Memorandum Submitted by the MRC to the House of Commons Select Committee on Science and Technology. London: MRC.

MRC, Medical Research Council 2002. MRC Submission to the House of Commons Science and Technology Committee: Scrutiny of the MRC. London: MRC. <http://tinyurl.com/ geomx> last accessed 5 April 2006.

Mulkay, M J 1972. The Social Process of Innovation: A Study in the Sociology of Science. London: Macmillan.

Mulkay, M J 1979. Science and the Sociology of Knowledge. London: Allen \& Unwin, p. 71.

Nowotny, Helga, Peter Scott and Michael Gibbons 2001. ReThinking Science: Knowledge and the Public in an Age of Uncertainty. Cambridge: Polity.

Nowotny, Helga, Peter Scott and Michael Gibbons 2003. Introduction: Mode 2 revisited: the new production of knowledge. Minerva, 41(3), 179-194.

OST, Office of Science and Technology 1993. Realising Our Potential: A Strategy for Science, Engineering and Technology. Presented to Parliament by the Chancellor of the Duchy of Lancaster, Cn 2250. London: HMSO.

Polanyi, Michael 1962. The Republic of Science: its political and economic theory; Minerva, 1, 54-73.

RCUK, Research Councils UK 2003. Synthesis of Strategies. Swindon: RCUK

RCUK, Research Councils UK 2004. Knowledge Transfer: Material World Knowledge Economy. Swindon: RCUK.

Richmond, Mark 1993. Mission in the market-place. Times Higher Education Supplement, 2 July, p. 9.

Rip, Arie 1994. The Republic of Science in the 1990s. Higher Education Studies, 28, 3-32.

Rip, Arie 1997. A cognitive approach to relevance of science. 
Social Science Information, 36, 615-640.

Rip, Arie and Barend van der Meulen 1996. The post-modern research system. Science and Public Policy, 23(6), 343-352.

Rosenberg, N and B R Nelson 1994. American universities and technical advance in industry. Research Policy, 23(3), 323-348.

Schimank, Uwe and Andreas Stucke 1994. A theoretical examination of the cases: why coping is often difficult and defective. In Coping with Trouble: How Science Reacts to Political Disturbances of Research Conditions, eds. Uwe Schimank and Andreas Stucke. New York: St Martin's Press.

Senker, Jacqueline, Wendy Faulkner and Lea Velho 1998. Science and technology knowledge flows between industrial and academic research: a comparative study. In Capitalising Knowledge, eds. Henry Etzkowitz, Andrew Webster and Peter Healey. Albany: State University of New York Press.

Shove, Elizabeth 2000. Reciprocities and reputations: new currencies in research. In The Future of Knowledge Production in the Academy, eds. M Jacob and T Hellstrom. Buckingham: Society for Research into Higher Education and Open University Press.

Stokes, Donald E 1997. Pasteur's Quadrant. Washington DC: Brookings Institution Press.
Trowler, Paul R 1998. Academics Responding to Change. Buckingham: Society for Research in Higher Education and Open University Press.

Van der Meulen, Barend 1998. Science policies as principal-agent games: institutionalization and path dependency in the relation between government and science. Research Policy, 27(4), 397-414.

Van der Meulen, Barend 2003. New roles and strategies of a research council: intermediation of the principal-agent relationship. Science and Public Policy, 30(5), 323-356.

Van der Meulen, Barend and Arie Rip 1998. Mediation in the Dutch science system. Research Policy, 27(8), 757-769.

Van der Meulen, Barend and Frank van der Most 2002. The role of the Norwegian research council in the dynamics of science: an ecological perspective on funding bodies. Paper for SPRU conference, Rethinking Science Policy: Analytical Frameworks for Evidence-Based Policy. Brighton, 21-23 March 2002.

Ziman, John 1987. Knowing Everything about Nothing: Specialization and Change in Research Careers. Cambridge: Cambridge University Press.

Ziman, John 1994. Prometheus Bound: Science in a Dynamic Steady State. Cambridge: Cambridge University Press. 